\title{
Analysis of Possibilities for Energy Recovery of Gaseous Products from the Gasifying Technologies
}

\author{
Marián Lázár ${ }^{1, *}$, Mária Čarnogurská ${ }^{1}$, Marta Lázárová ${ }^{1}$, Michal Kubík ${ }^{1}$ and Juraj Václav ${ }^{1}$ \\ ${ }^{1}$ Technical University in Košice, Faculty of Mechanical Engineering, Department of Power Engineering, Slovac Republic
}

Abstract: The paper is aimed at describing the innovative possibility of the thermal treatment of selected types of waste using plasma reactor as a new progressive and promising technology. Attention is also given to energy recovery of mixed synthesis gas by combustion engines.

Keywords: plasma technology; syngas; combustion engine.

\section{Introduction}

The idea of gasification of a low-grade primary fuel, such as e.g. brown coal, existed and was examined decades ago. Gasification of waste products becomes increasingly important, especially now.

The gasification process can be described as a series of thermo - chemical sequences, in which there is a simultaneous conversion of the raw material of highcarbon to gaseous products. The conversion itself, of the pure carbon monoxide (using air as the oxidizing agent), is characterized by the relationship of the partial carbon oxidation (1) and (2).

$$
\begin{array}{ll}
\mathrm{C}+\frac{1}{2 \mathrm{O}_{2}}=\mathrm{CO} & \Delta \mathrm{H}_{298}^{0}=-111 \mathrm{~kJ} \cdot \mathrm{mol}^{-1} \\
2 \mathrm{C}+\mathrm{O}_{2}=2 \mathrm{CO} & \Delta \mathrm{H}_{298}^{0}=-221 \mathrm{~kJ} \cdot \mathrm{mol}^{-1}
\end{array}
$$

By mixing oxygen and water vapor there is also, except for the partial oxidation reaction of the carbon, a reaction of the vapor-carbon [3]

$$
\begin{aligned}
& \mathrm{C}+\mathrm{H}_{2} \mathrm{O}=\mathrm{H}_{2}+\mathrm{CO} \quad \Delta \mathrm{H}_{298}^{0}=+131 \mathrm{~kJ} \cdot \mathrm{mol}^{-1} \\
& 2 \mathrm{C}+2 \mathrm{H}_{2} \mathrm{O}=2 \mathrm{CO}+2 \mathrm{H}_{2} \quad \Delta \mathrm{H}_{298}^{0}=+90 \mathrm{~kJ} \cdot \mathrm{mol}^{-1}
\end{aligned}
$$

And water-gas shift reaction

$\mathrm{CO}+\mathrm{H}_{2} \mathrm{O}=\mathrm{CO}_{2}+\mathrm{H}_{2} \quad \Delta \mathrm{H}_{298}^{0}=-41 \mathrm{~kJ} \cdot \mathrm{mol}^{-1}$

Providing the thermal equilibrium, the decomposition reaction takes place according to the equation (6), allowing for a gasification of a mixture of oxygen and water vapor (the combination of equations (2) and (4))

$$
4.08 \mathrm{C}+\mathrm{O}_{2}+2.08 \mathrm{H}_{2} \mathrm{O}=4.08 \mathrm{CO}+2.08 \mathrm{H}_{2}
$$


Gas mixture produced in this way would be ideally made up of $66 \% \mathrm{CO}$ and $34 \% \mathrm{H}_{2}[1,2]$.

By a gasification of a real fuel (coal, petroleum products, waste) the produced gas mixture contains (other than carbon monoxide and hydrogen, which are dominant characteristics in the composition), also other substances such $\mathrm{CO}_{2}, \mathrm{CH}_{4}, \mathrm{C}_{n} \mathrm{H}_{m}, \mathrm{~N}_{2}, \mathrm{H}_{2} \mathrm{O}, \mathrm{O}_{2}$ and the like. Nitrogen that forms the ballast while reducing the heating value of the resulting gas mixture could be derived simply from the raw material (from the primary or secondary source of fuel) entering the gasification process, or from an external source. This depends on the used technology. The presence of organic ingredients $\mathrm{CO}_{2}, \mathrm{O}_{2}$, and $\mathrm{H}_{2} \mathrm{O}$ in the gas mixture are indicatives of imperfections predicted from the sequences of chemical reactions 1 to 6 . Methane and higher hydrocarbons are released from the fuel in the decomposition of high-molecular chains. The gasification process is therefore more complex than in the case of plain carbon gasification at ideal conditions. The overall number of chemicalthermal sequences at the conversion process of the fuel into gas products is extensive.

Depending on boundary conditions of the gasification process as well as on the construction of the reactor, it is possible that some of the higher hydrocarbons are, due to imperfections in the undergoing chemical reactions, rapidly released from the fuel. Those hydrocarbons are represented in the resulting mixture in low concentrations.

\section{Description of the gasifier}

A key element of the gasifier (Plasma reactor) that uses the gasification processes and the melting of the waste in order to obtain a synthesis gas (Fig. 1) is a plasma arc torch with a dependent arc. The torch generates a plasma arc discharge between a hollow graphite electrode and graphite crucibles, forming the bottom of the plasma reactor. The hollow graphite electrode (placed in the holder) is supplied by a flexible copper cable. The vertical movement of the electrode is ensured by programmed actuator through a sliding mechanism. The supply of plasma gas (usually an inert nitrogen or argon) into the arc discharge is provided through the opening located in the center of the cathode. The anode consists of a graphite crucible; the power supply is provided by three graphite and steel bars. Their cooling is ensured by the air cooler, located under the body of the reactor, or through a free cooling [4].

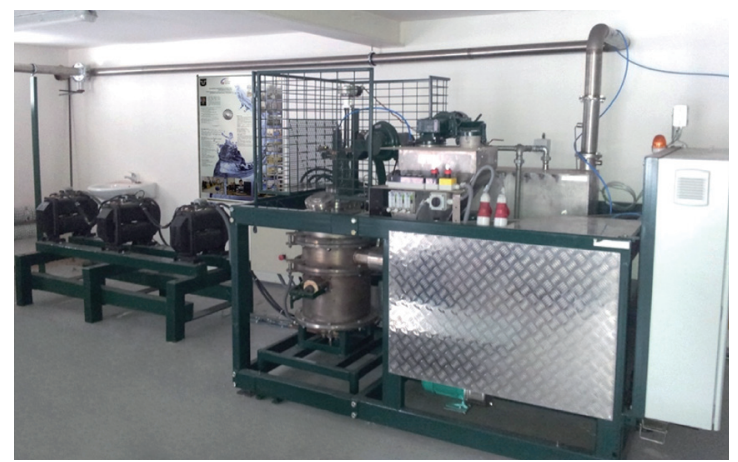

Fig. 1: Plasma reactor.

By approaching the refractory electrodes to the distance that is sufficient to create an electrical arcing the electric current begins to flow between them. The electrical resistance between the electrodes rapidly heats the area near the touchelectrode, resulting in electrons being emitted from the cathode surface. In the axis of the negative electrode there is a concentrically milled hole intended to feed the gaseous medium ( $\mathrm{N}_{2}$, Ar or the like.) into the arc discharge. The flow of electrons released from the cathode and from the gaseous media closes the electric circuit between the electrodes, whereby the gas in the electrode is further heated. The ion shower on the cathode, the release of electrons and their flow towards the anode as well as the ongoing collision between the ions and the neutral gas particles causes the excitement of particles. After reaching sufficiently high energy levels, dissociation and weak gas ionization occurs. The maintenance of the process of generating weakly ionized plasma is ensured through a constant updating of electricity into discharge. By interrupting the direct current power supply a recombination of the ionized particles occurs and the discharge quickly extinguishes.

The organic portion of the processed charge (brown coal, coal sludge, RDF, municipal waste), relative to the presence of oxygen in waste or to the sub-stoichiometric amount of the oxidizing agent in the reaction chamber, is oxidized in the reactor as a result of the influence of high temperatures into gaseous products $\left(\mathrm{H}_{2}, \mathrm{CO}, \mathrm{CO}_{2}, \mathrm{CH}_{4}\right.$, and so on). The inorganic portion of the waste, depending on the temperature in the reaction chamber, is 
transferred into liquid phase and it is concentrated on the bottom of the reactor as a liquid slag or an alloy (in case the batch from waste contains metal oxides that reduce under the given boundary conditions) [7]. The tapping of these by-products of the plasma processing of the charge is provided via a tap-hole that is located close to bottom of the reactor $[1,3]$.

\section{Experimental gasification and energy recovery of synthesis gas}

By the gasification of fuel (waste with high carbon content) in an inert (nitrogen, argon) or slightly oxidizing atmosphere, the combustible gas components such as $\mathrm{CO}, \mathrm{H}_{2}, \mathrm{CH}_{4}$ are obtained. Their proportion ratio within the resulting synthesis gas is significantly influenced by the operating conditions used in the gasification process (atmosphere type, oxidation agent, operating pressure, temperature, time, etc.). Tab.1 shows the summary results of the composition of the synthesis gas produced by gasification of four types of waste in a plasma reactor with a dependent arc with a hollow graphite electrode. Four types of used waste are: a brown coal, coal sludge, RDF waste and municipal waste.

Table 1: Composition of the synthesis gas obtained from gasification of different waste type.

\begin{tabular}{|c|c|c|c|c|c|c|}
\hline \multirow[b]{2}{*}{ Component } & \multicolumn{6}{|c|}{ Composition of samples taken from the synthesis gas } \\
\hline & $\begin{array}{c}\text { Waste brown coal(moa) } \\
\text { (vol. \%) }\end{array}$ & $\begin{array}{c}\text { Waste brown coal(Moa) } \\
\text { (vol. \%) }\end{array}$ & $\begin{array}{l}\text { Coal sludge } \\
\text { (vol. \%) }\end{array}$ & $\begin{array}{l}\text { RDF }^{(1 \mathrm{n} .)} \\
\text { (vol. \%) }\end{array}$ & $\begin{array}{l}M W^{(\text {(in.) }} \\
\text { (vol. \%) }\end{array}$ & $\begin{array}{l}M W^{(\text {(n.) })} \\
(\text { vol. \%) }\end{array}$ \\
\hline Methane $\left(\mathrm{CH}_{4}\right)$ & 6.34 & 0.48 & 0.02 & 0.82 & 8.59 & 4.77 \\
\hline Hydrogen $\left(\mathrm{H}_{2}\right)$ & 35.1 & 44.8 & 32.9 & 39.2 & 44.5 & 48.9 \\
\hline Oxygen $\left(\mathrm{O}_{2}\right)$ & 1.62 & 0.24 & 0.02 & 0.04 & 0.16 & 0.11 \\
\hline Nitrogen ( $\mathrm{N}_{2}$ ) & 23.2 & 9.23 & 20.1 & 17.4 & 6.03 & 6.61 \\
\hline Carbon dioxide $\left(\mathrm{CO}_{2}\right)$ & 10.0 & 0.68 & 3.35 & 3.3 & 6.60 & 1.66 \\
\hline Carbon monoxide (CO) & 22.6 & 44.4 & 43.6 & 39.1 & 32.5 & 37.1 \\
\hline Ethen $\left(\mathrm{C}_{2} \mathrm{H}_{4}\right)$ & 0.16 & 0.043 & 0.001 & 0.068 & 0.97 & 0.49 \\
\hline Ethane $\left(\mathrm{C}_{2} \mathrm{H}_{6}\right)$ & 0.35 & 0.0036 & 0.001 & 0.003 & 0.055 & 0.031 \\
\hline Ethyne $\left(\mathrm{C}_{2} \mathrm{H}_{2}\right)$ & 0.0006 & 0.036 & 0.001 & 0.010 & 0.42 & 0.24 \\
\hline Sum of $C_{3}$ hydrocarbons & 0.22 & 0.0027 & 0.001 & 0.007 & 0.011 & 0.004 \\
\hline Sum of $\mathrm{C}_{4}$ hydrocarbons & 0.11 & 0.0032 & 0.001 & 0.001 & 0.0099 & 0.004 \\
\hline Sum of $C_{5-8}$ hydrocarbons & 0.15 & 0.05 & 0.01 & 0.001 & 0.17 & 0.12 \\
\hline Lower heating value $\left(\mathrm{MJ} \cdot \mathrm{m}^{-3}\right)$ & 9.82 & 10.75 & 9.07 & 9.52 & 13.12 & 12.31 \\
\hline $\begin{array}{l}\text { Pot. Volume production } \\
\left(\mathrm{m}^{3} \cdot \mathrm{kg}^{-1}\right)^{*}\end{array}$ & 0.214 & 0.352 & 1.419 & 1.125 & 1.069 & 0.973 \\
\hline
\end{tabular}

* based on nitrogen balance

MW - municipal waste, RDF - Solid recovered fuel produced by the separation of flammable components MW (refuse derived fuel), (MOA) slightly oxidized atmosphere, ${ }^{(i n)}$ - inert atmosphere.

Experiments related to the waste gasification processes listed in Tab. 1 underwent a change in an inert and slightly oxidizing atmosphere. Grain size of the waste was adjusted to less than $5 \mathrm{~mm}$. The exception was the brown coal waste that was loaded into the reaction chamber of the plasma reactor with a size of approximately $10 \mathrm{~mm}$. The temperature in the reaction chamber of the plasma reactor during the gasification process was maintained at an approximately constant level for each experiment. The temperature ranged between $1350-1450^{\circ} \mathrm{C}$ [1].

Syngas or synthesis gas produced during the gasification process contained the inert and combustible components with a proportional ratio specified in Tab. 1 and has properties suitable for further usage e.g. production of heat and electricity $[5,6,8]$. The gasification experiments of 
various kinds of waste were conducted in order to obtain information on the composition and quality of the gas as a by-product of a thermal waste treatment. Based on this information, it was possible to artificially prepare such a gas mixture that would, in regards to their composition and quality, correspond with a gas actually arising in the process of the waste disposal.

Due to lack of information associated with the direct use of synthesis gas generated in this manner in combustion plants, while carrying out experiments intended at energy use of synthesis gas, an artificially prepared gas mixture was considered. During the experiment, the mixture was stored inside a pressure vessel. An artificially pre-mixed blend of synthesis gas contained four most dominant gases $\left(\mathrm{CH}_{4}, \mathrm{CO}, \mathrm{H}_{2}\right.$, and $\mathrm{N}_{2}$ ) represented in real samples taken from the synthesis gas in a plasma gasification of RDF and municipal waste. Similarly, the mixture met the technological and safety requirements applicable to the storage of explosive gas mixtures in pressure vessels. The percentage ratio of components in the finished synthesis gas mixture corresponds to a value of 4 wt. \% $\mathrm{H}_{2}, 40$ wt. \% CO, 5 wt. \% $\mathrm{CH}_{4}$ and 10 wt. \% $\mathrm{N}_{2}$

In an attempt to evaluate the energy recovery of synthesis gas the combustion engine was used. The engine in the experiments was a fourcylinder SI engine of Opel Ascona 1.6. Its technical specifications are: working volume of $1584 \mathrm{~cm}^{3}$, $85 \mathrm{~mm}$ bore, $69.8 \mathrm{~mm}$ stroke, power $55 \mathrm{~kW}$ at $5000 \mathrm{rpm} \cdot \mathrm{min}^{-1}$, compression ratio of 8.8:1, number of two valves per cylinder (2), original fuel: 95 octane gasoline.

The original system, which served to prepare the fuel mixture for spark ignition engines from easily vaporizable liquid fuels, was modified into a system enabling a burning of gaseous fuel blends (a gaseous fuel mixer was installed). Mechanical performance of the four-cylinder petrol combustion engine to an asynchronous generator (TGL 11856/01, type KHR 132 M4) is transmitted through the shaft. The asynchronous generator mainly used for cogeneration units with a low power (up to $100 \mathrm{~kW}$ ), works in parallel with a parent power system.

The assembly of the internal combustion engine and the energy recovery of the artificially prepared gas mixture (SG) correspond to the simplified diagram in Fig. 2.

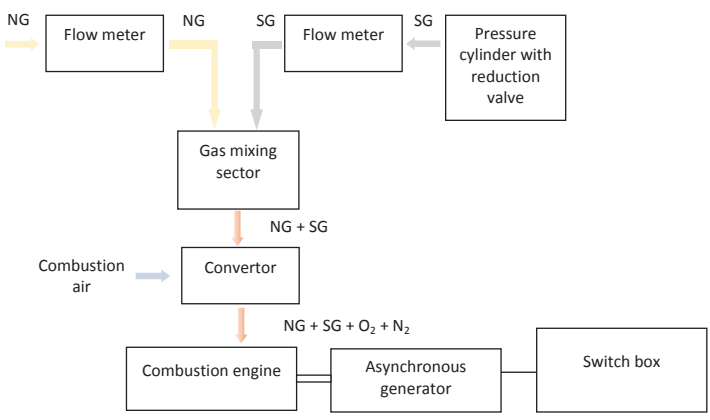

Fig. 2: The schematic diagrams of the experimental setup.

During the combustion of the specified gas mixture in a given combustor, the production of $\mathrm{CO}$ in the flue gas has been monitored. Assessment of the oxygen and carbon monoxide proportion, as well as the flue gas temperature and ambient temperature measuring ( $\left.T_{\mathrm{ok}}\right)$ was ensured by the Testo 330. At the same time, the average consumption of natural gas used with the synthesis gas mixture was determined using gas flow meters. We limited the value when mixing the gaseous fuel In order to maintain the proportion of hydrogen in a gas mixture below 16\% (safety limit for the faultless operation of the petrol engine established by the operator).

After the process optimization of the natural gas combustion (regulation of combustion air and fuel intake), a dosage of synthesis gas into supplied natural gas was introduced (Fig. 2) into the convertor. During the experiment the changes in the gas consumption, voltage and current values at the generator clamps and the flue gas temperature $\left(T_{s}\right)$ were monitored, as well as the $\mathrm{O}_{2}$ values, and the $\mathrm{CO}$ content in the flue gas. Values of the average natural and synthesis gas consumption are shown in Tab. 3, along with the data defined by means of the flue gas analyzer. The course of changes in performance of the power generator is shown in Fig. 3.

\section{Result and discussion}

By mixing $4.8 \mathrm{l} \cdot \mathrm{min}^{-1}$ of synthesis gas with $84.4 \mathrm{l} \cdot \mathrm{min}^{-1}$ of natural gas, an increase of $\mathrm{CO}$ emissions in the exhaust gas occurred (Tab. 3, column 1). By varying the natural gas flow to $83.4 \mathrm{l} \cdot \mathrm{min}^{-1}$, along with an additional controlled supply of combustion air, the CO emissions were 
Table 2: Actual formulation of the dosing fuel mixture during the experiment.

\begin{tabular}{|c|c|c|c|c|c|c|c|}
\hline \multicolumn{3}{|c|}{ Fluel flow (l·min-1) } & \multicolumn{4}{|c|}{ Composition of the gas mixture (vol. \%) } & \multirow{2}{*}{$\begin{array}{l}\text { Lower heating } \\
\text { value }\left(\mathbf{k} \cdot \mathrm{m}^{-3}\right)\end{array}$} \\
\hline Natural gas & Syngas & Total flow & $\mathrm{CH}_{4}$ & $\mathrm{H}_{2}$ & co & $\mathrm{N}_{2}$ & \\
\hline 83.4 & 4.8 & 88.2 & 94.83 & 2.45 & 2.18 & 0.54 & 32597 \\
\hline 78.0 & 9.2 & 87.2 & 89.98 & 4.75 & 4.22 & 1.06 & 31462 \\
\hline 70.0 & 17.5 & 87.5 & 81.00 & 9.00 & 8.00 & 2.00 & 29361 \\
\hline 58.7 & 25.1 & 83.8 & 71.55 & 13.48 & 11.98 & 3.00 & 27151 \\
\hline 52.0 & 33.5 & 85.5 & 62.78 & 17.63 & 15.67 & 3.92 & 25099 \\
\hline
\end{tabular}

Table 3: Actual formulation of the dosing fuel mixture during the experiment.

\begin{tabular}{|c|c|c|c|c|c|c|}
\hline \multirow{2}{*}{ Measured values } & \multicolumn{6}{|c|}{ Fuel } \\
\hline & $N G+S G$ & $N G+S G$ & NG+SG & $N G+S G$ & $N G+S G$ & $N G+S G$ \\
\hline Natural gas flow $\left(1 \cdot \mathrm{min}^{-1}\right)$ & 84.4 & 83.4 & 78 & 70 & 58.7 & 52 \\
\hline Synthesis gas flow $\left(I \cdot \mathrm{min}^{-1}\right)$ & 4.8 & 4.8 & 9.2 & 17.5 & 25.1 & 33.5 \\
\hline $\mathrm{O}_{2}(\%)$ & 7.4 & 7 & 6.9 & 6.5 & 6.9 & 8.4 \\
\hline CO (ppm) & 2271 & 655.6 & 501 & 430 & 399 & 461 \\
\hline$T_{s}\left({ }^{\circ} \mathrm{C}\right)$ & 201.8 & 201.8 & 201.5 & 207.8 & 205.9 & 203.4 \\
\hline Tok $\left({ }^{\circ} \mathrm{C}\right)$ & 16.5 & 16.5 & 16.7 & 17 & 17.2 & 17.5 \\
\hline
\end{tabular}

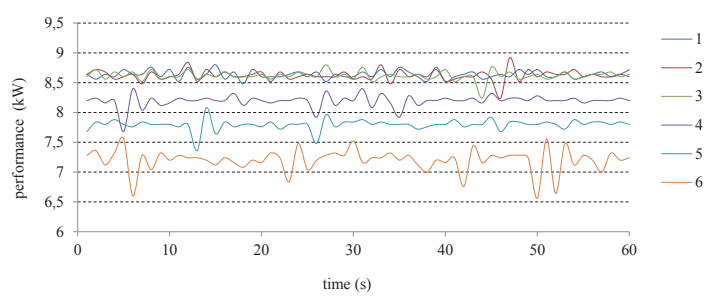

Fig. 3: Course of the charge of the generator performance depending on the composition of the fuel mixture.

(note: 1 - natural gas; 2 - natural gas $+4.81 \cdot \mathrm{min}^{-1} \mathrm{SG} ; 3$ - natural gas $+9.21 \cdot \mathrm{min}^{-1} \mathrm{SG} ; 4$ - natural gas $+5.171 \cdot \mathrm{min}^{-1} \mathrm{SG} ; 5$ - natural gas $+1.251 \cdot \mathrm{min}^{-1} \mathrm{SG} ; 6$ - natural gas $\left.+33.51 \cdot \mathrm{min}^{-1} \mathrm{SG}\right)$

stabilized at a value close to 655 ppm (Tab. 3). Following this intervention the position of valves regulating the natural gas flow and combustion air, remained unchanged until the end of the experiment.

In the subsequent phases of the measurement, the ratio of the synthesis gas mixture supplying the gaseous fuel entering the combustion engine increased, resulting in a reduction of the $\mathrm{CO}$ emissions in the flue gas. The $\mathrm{CO}$ emission limit in exhaust gases at stationary gas engines is established by law no. 706/2002 L.C. to the value of $650 \mathrm{mg} \cdot \mathrm{m}^{-3}$.

Other emissions found in flue gas are $\mathrm{NO}_{x}$ emissions; the emission limit for $1 \mathrm{~m}^{3}$ of flue gas is $250 \mathrm{mg}$. For engines using the natural gas this value, in most cases, is attainable. Providing there is a larger production of NOx emissions, the reduction can be achieved by a suitable alteration of the engine settings; for example by reducing the advanced ignition or by a fuel mixture enleanment. The combustion process of the fuel gas mixture containing a high amount of inert gas has for the object to achieve a quality combustion process with the air excess $n>>1$. In this case certain construction design measures are required, typically consisting of an optimization of the combustion space and the ignition system located in the cylinder.

By dosing 4.8 I and 9.2 I of synthesis gas per minute into natural gas of $78-83.4 \mathrm{l} \cdot \mathrm{min}^{-1}$ we achieved the performance of the electric generator with no significant changes. At the given flow rates, the volume of methane in the fuel mixture is above $89 \%$ and compared to the generator performance at the cogeneration unit operation using natural gas, a drop in performance power generator of $0.02 \mathrm{~kW}$ is recorded, ie to $8.62 \mathrm{~kW}$ (a value valid for both synthesis gas flows). A more significant drop in performance occurred while the flow of synthesis gas increased to $17.5 \mathrm{I} \cdot \mathrm{min}^{-1}$. In this 
phase of the experiment, the average value of the generator performance was estimated at $8.2 \mathrm{~kW}$. By increasing the ratio of synthesis gas in the fuel mixture, the combustion engine performance was further reduced. The poorer mixture of gaseous fuel at a flow rate of $25.1 \mathrm{I} \cdot \mathrm{min}^{-1}$ caused a loss in performance which averaged to $7.8 \mathrm{~kW}$. For the flow of synthesis gas in an amount of $33.5 \mathrm{l} \cdot \mathrm{min}^{-1}$ the average generator performance was measured to $7.2 \mathrm{~kW}$. At the given performance, the ratio of methane in the fuel represented about $63 \%$ of the entire volume. The dependence of the efficiency of the electric power generation on the synthesis gas flow is shown in Fig. 4.

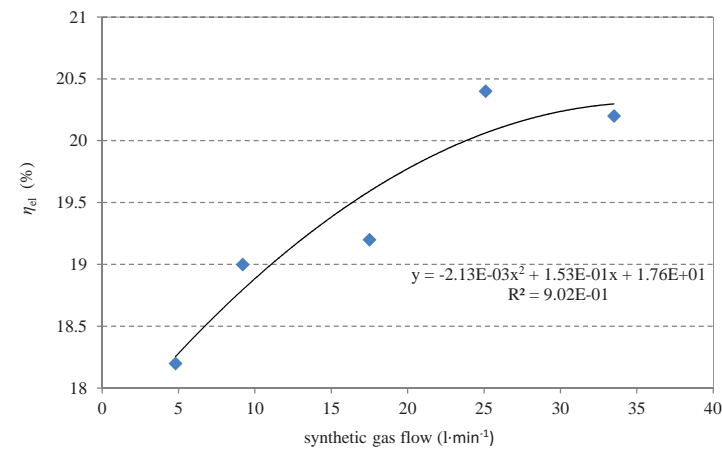

Fig. 4: Dependence of the efficiency of electricity generation on the SG flow.

Based on the calculated values of the efficiency of the electric power generation, valid for the described experiment of the synthesis gas energy recovery, and the dependency of the efficiency of the electricity generation on the SG flow, it could be concluded that the performance rises with a steadily growing ratio of synthesis gas in the fuel gas mixture. This trend is visible until the dosing reaches an amount of $25.1 \mathrm{l} \cdot \mathrm{min}^{-1}$ of synthesis gas. By a further increase in the SP flow, the efficiency reaches a break point and decreases by almost $0.5 \%$. This decrease is likely due to the deterioration of the combustion process in the cylinder, as supported by the data measured with a flue gas analyzer (Tab. 3).

Conclusions valid for the accomplished experiment could be defined as follows:

- By blending the purified synthesis gas to the supplied natural gas before entering the combustion engine, there is a real possibility of the energy recovery from the syngas produced in the gasification process. Gasification of the waste with a high proportion of the organic fraction also brings, besides the hygienic disposal and waste reduction, the benefit in the form of energy recovery of otherwise unused waste that usually ends up on the black or controlled landfills,

-Dosage of synthesis gas into natural gas before entering the combustion engine yielded a reduction of $\mathrm{CO}$ in the exhaust gas by 30 $40 \%$. By burning a mixture of synthesis gas and natural gas in cogeneration units, with a fully automated dosing control of the combustion air, fuel and the emerging emissions, an operation of environmentally friendly power generation could be presumed. It is necessary to validate this argument, for a pilot system of the waste plasma gasification in which a purified synthesis gas will be recovered in the cogeneration system,

- In the combustion of the gaseous fuel mixture, which corresponds to the values indicated in the Tab. 2, no operational problems were recorded. A reduced resistance to the knocking in the cylinder (misfiring) was not observed even at the volume fraction of hydrogen in the fuel at $17.63 \mathrm{vol}$ \%.

\section{Conclusions}

Production of a gaseous mixture, with majority of hydrogen and carbon monoxide, is a potential source of energy available for national economy and represents a quality input for the chemical industry. Hydrogen, which constitutes a significant percentage of the gas mixture generated during the high-temperature gasification, is considered to be the most viable alternative to fossil fuel and does not contribute to the greenhouse effect.

The first tests in the gasification reactor confirmed the possibility of a waste gasification using the plasma technology from technological point of view; however, only further experiments and tests will confirm the economic justification of this technology. In the experiment, the set values of the synthesis gas production are rather indicative. Their precise determination requires an extensive research process in a pilot scheme involving the reactor. The results of the research on the energy recovery using the syngas combustion petrol engine reveal the real possibility of the electrical energy production from the mechanical power which is produced by the chemical energy in the combustion process. Adding the synthesis gas into 
the natural gas resulted in the reduction of the CO emissions produced during the combustion of the gas mixture as well as in the improvement of the efficiency of fuel energy use.

\section{Acknowledgments}

The article was created with the support of Ministry of Education for the EU Structural Funds Operational Program "Research and Development" project no. p. ITMS 26220220044 Project and VEGA 1/0004/2014.

\section{References and notes}

[1] Čarnogurská, M., Lázár, M. (2013). Plazmové spracovanie a zhodnocovanie odpadu. Košice: TU, ISBN 978-80-553-15140 .

[2] Jílek, J. (1953). Moderní způsoby zplynování paliv kyslíkem. Praha: Státní nakladatelství technické literatury.

[3] Martišovitš, V. (2006). Základy fyziky plazmy. Učebný text pre 3. ročník magisterského štúdia. UK Bratislava, ISBN 80-2231983-X.

[4] Imriš, I., Klenovčanová, A. (2009). The plasma gasification and smelting unit. Acta mechanica Slovaca, vol. 13, vol. 2, p. 6-11.

[5] Lukáč, L., Kuna, Š., Kizek, J., Repášová, M. (2013). Design of methodology for wood chips moisture estimation determined for gasification. Experimental fluid Mechanics 2013, p. 429-432.

[6] Kočanová, S., Lukáč, L., Széplaky, D., Lazić, L. (2014). The impact of contaminated biomass for the formation of emission in the combustion process of producer gas in the cogeneration. The application of experimental and numerical methods in fluid mechanics and energetic 2014, p. 123-127.

[7] Čarnogurská, M., et. al. (2015). Measurement and evaluation of properties of MSW fly ash treated by plasma. Measurement, vol. 62, p. 155-161.

[8] Lázár, M., et. al. (2015). High-temperature gasification of RDF waste and melting of fly ash obtained from the incineration of municipal waste. Acta Polytechnica, vol. 55, vol. 1, p. 1-6.

\section{Biographical notes}

Ing. Marián Lázár, PhD., (1985) he is a research scientist and graduate of Faculty of Mechanical Engineering, Technical University in Košice. His scientific and research work focuses on the field of waste treatment by plasma technology, renewable energy resources and in the area of production and storage of hydrogen.

prof. Ing. Mária Čarnogurská, CSc., (1953) she is a graduate of Faculty of Mechanical Engineering, Technical University in Košice (TUKE). Currently works as a head of Department of Power Engineering at Faculty of Mechanical Engineering. Her long-term professional focus is within the area of power engineering. The research is concentrated on mathematical and physical modeling of processes and effects applied in power engineering, the flow of different media in energy machines and appliances as well as the exploitation of non-utilised heat energy in diverse industrial applications.

Ing. Marta Lázárová, PhD., (1987) she is a graduate of Faculty of Mechanical Engineering, Technical University of Košice. She actively participates in research of new technologies in area of renewable energy resources and in the area of high temperature gasification of various type of wastes.

Ing. Michal Kubik, (1978) he is a PhD. student and graduate of Faculty of Mechanical Engineering, Technical University of Košice. He actively participates in research of new technologies in area of fluid flow.

Ing. Juraj Václav, (1957) he is a PhD. student and graduate of Faculty of Mechanical Engineering, Slovak Technical University of Bratislava. He actively participates in research of Nuclear Materials. 